\title{
IDENTIDADE RELIGIOSA E RECONSTRUÇÕES DE SI: PERFORMANCES LGBT CRISTÃS ENTRE A TRANSFORMAÇÃO E A NORMATIVIDADE
}

FIELDER, Bronwyn; EZZY, Douglas. Lesbian, Gay, Bisexual and Transgender Christians: Queer Christians, Authentic Selves. London \& New York: Bloomsbury, 2018.

Tainah Biela Dias*

A obra de autoria de Bronwyn Fielder e Douglas Ezzy é, certamente, uma contribuição fundamental para o campo de estudos que se ocupam da análise do fenômeno religioso, suas transformações e sua complexidade nas sociedades contemporâneas. Além disso, trata-se de marco importante para o campo específico que procura refletir sobre as relações e intersecções entre religiosidades/espiritualidades e questões de gênero e sexualidades envolvendo, sobretudo, sujeitos que não se conformam à chamada heteronormatividade, ou seja, arranjos normativos que pressupõem a normalidade da heterossexualidade cisgênero em detrimento de outras expressões e vivências performáticas, estéticas, sexuais e afetivas.

A pesquisa desenvolvida pelos autores aborda processos de construção e reconstrução de si - self - e da identidade coletiva de sujeitos que frequentam quatro congregações religiosas filiadas à Fraternidade Universal das Igrejas da Comunidade Metropolitana (FUICM) ${ }^{1}$ em solo australiano, especificamente nas cidades de Sydney e Melbourne. Neste processo de conflitos, confrontos, enfrentamentos, negociações e

* Doutoranda e Mestra em Ciências da Religião pelo Programa de Pós-Graduação em Ciências da Religião da Universidade Metodista de São Paulo (UMESP). Bacharela e licenciada em Ciências Sociais pela Pontifícia Universidade Católica de Campinas (PUC-Campinas). Bolsista da Coordenação de Aperfeiçoamento de Pessoal de Nível Superior (CAPES).

Universal Fellowship of the Metropolitan Community Churches (UFMCC), no original. 
reconciliações estabelecidos pelos sujeitos religiosos frente à tradição na qual foram formados, são ressaltados processos que impactam profundamente a reformulação de uma identidade comumente entendida como controversa ou mesmo contraditória: o/a/e cristão/a/e LGBT.

Dividida em oito capítulos, inclusos nestes números a Introdução e a Conclusão, Fielder e Ezzy elaboram uma organização coerente entre as partes que compõem a obra. Logo no início, os autores apresentam os referenciais teórico-metodológicos que vão perpassar toda a obra e auxiliar nas análises que se seguem acerca das vivências sociorreligiosas de pessoas LGBT cristãs. A noção de ética de autenticidade inspirada por Charles Taylor (1991), assim como a conceptualização de habitus religioso formulada por Pierre Bourdieu (1977) são nucleicas para compreender as transformações da identidade dos sujeitos que compõem a pesquisa. As reflexões de Fielder e Ezzy se centram nas formas pelas quais LGBTs que proclamam a fé cristã procuram assumir uma identidade autêntica que permita a integração entre sua religiosidade e sua sexualidade e/ou identidade de gênero a despeito das percepções religiosas estigmatizantes e condenatórias. Neste processo, o cristianismo tal qual formulado e praticado pelas Igrejas da Comunidade Metropolitana (ICMs) ${ }^{2}$ assume papel de empoderar os sujeitos em busca dessa autenticidade perante si e outres. Da mesma forma, é no convívio comunitário com pessoas com histórias similares e em novas possibilidades rituais oferecidas pelas ICMs que o habitus religioso progressivamente se transforma. Por fim, ao final da obra, os autores apresentam as formas pelas quais as MCCS impactam e transformam o cristianismo, assim como seus limites de atuação e transgressão normativa. Falaremos desses aspectos de forma mais detalhada nos parágrafos que se seguem.

O capítulo introdutório do livro se ocupa em fornecer um panorama mais geral dos debates envolvendo religiões - mais especificamente o cristianismo - e identidades LGBT. Para isso recupera produções bibliográficas que analisam como pessoas que não se conformam à heteronormatividade são entendidas como pecaminosas dentro da tradição cristã hegemônica. Explora, também, as transformações religiosas na contemporaneidade, que permitem aos sujeitos religiosos maior

Metropolitan Community Churchs (MCCs), no original. 
autonomia para decidir a respeito de suas formas de crer, assim como avanços importantes em termos de conquistas e visibilidade de pautas diretamente ligadas ao movimento pelos direitos LGBT. Este cenário cada vez mais complexo permite, em grande medida - e a despeito de resistências de caráter conservador -, a pluralização das formas de exercer a fé e, no caso da pesquisa em particular, o próprio cristianismo.

O segundo capítulo, intitulado Queer Authentic Christian Lives se ocupa de explicitar o arcabouço teórico que permitirá dar conta das análises subsequentes. Alguns aspectos fundamentais aqui são a noção de que pessoas LGBT cristãs buscam formas de viver autênticas e que permitam a coexistência entre suas identidades sexuais e/ou de gênero e a religiosidade cristã. Assumir a verdade sobre si para si e para Deus é parte da trajetória desses sujeitos, sobretudo na medida em que se aposta em um discurso essencialista que percebe a sexualidade e/ou identidade de gênero como elementos dados por Deus (God-given). Exploram, também, as formas pelas quais as identidades individuais são profundamente afetadas pelas relações que os sujeitos estabelecem nos mais diversos ambientes, enfatizando o papel central de grupos como as congregações religiosas. No caso de membros/as/es das ICMs, os depoimentos coletados por meio de entrevistas em profundidade, revelam que viver de forma autêntica, para esses sujeitos, só é possível a partir do convívio comunitário e do reconhecimento por parte do grupo, possibilitando formas de empoderamento que viabilizam o processo de se assumir (coming out), na medida em que o indivíduo passa a proclamar publicamente sua verdadeira identidade.

Muito embora esta noção de verdadeira identidade se contraponha às proposições da chamada Teoria Queer, que possui uma abordagem fundamentalmente construtivista no que concerne à produção de identidades, noções de caráter essencialista parecem ser fundamentais para pessoas LGBT cristãs, na medida em que são justificadas pela própria noção da identidade como dada por Deus. Pesquisas precedentes (i.e.: Ronald ENROTH; Gerald JAMISON, 1974; Paul BAUER, 1976; Bill LUKENBILL, 1998; Melissa WILCOX, 2001; 2003) também enfatizam este aspecto e o atribuem, por vezes, a uma teologia pentecostal caracteristicamente relacionada à figura de Troy Perry, fundador e principal liderança da 
denominação até os dias atuais. Este é um aspecto chave que percorre toda a análise e que está intimamente ligado à noção de religião como relacional, experiencial e emocional. Tratam-se, portanto, de processos complexos que envolvem a experiência de sujeitos que, aparentemente, contradizem os princípios de sua própria tradição, mas que na verdade agem sobre ela como agentes de transformação.

The Metropolitan Community Churches é o nome do terceiro capítulo da obra, que se ocupa em explicitar aspectos históricos da formação das ICMs, primeiramente, nos Estados Unidos no ano de 1968, pelo ministro pentecostal Troy Perry. A denominação foi fundada depois de Perry ser excomungado da igreja onde exercia seu pastorado, por conta de ter se assumido homossexual. Assim, são apresentadas algumas características mais gerais da FUICM enquanto instituição religiosa, tal qual o compromisso com o enfrentamento à epidemia do HIV/Aids, o compromisso nacional e internacional com pautas relacionadas à igualdade de direitos e respeito à diversidade - fator que não impede a existência de tensões no cotidiano das comunidades locais.

No contexto australiano, Fielder e Ezzy percebem o caráter ecumênico das ICMs. A diversidade de práticas e expressões religiosas durante o culto, assim como constantes transformações, podem até mesmo causar a impressão da existência recorrente de instabilidades e tensões. Para exemplificar este elemento, os autores enfatizam que enquanto uma das comunidades pesquisadas possui similaridades com relação à Igreja Anglicana (Anglican Church), outra aparente ser influenciada pela Igreja Unida da Austrália (Uniting Church) e outra possui traços Metodistas (Wesleyan Methodism). Entretanto, de forma geral, impera entre os/as/es interlocutores/as de pesquisa a noção de que a MCC é um espaço seguro, no qual noções como casa e família são constantemente acionadas, assim como a ideia de que é um espaço que permite ao sujeito ser quem realmente é, corroborando com a noção de busca por autenticidade mencionada anteriormente. Enfatizam, ainda, que para os membros das MCCs que compõem a pesquisa, a noção de que a congregação que frequentam se propõe ser radicalmente inclusiva parece ser um elemento fundamental que concorre para a formação do habitus religioso daqueles/as que a integram.

Seeking an Authentic Self é o nome do quarto capítulo que compõe 
o livro e dá centralidade às vivências individuais e aos processos de construção da identidade e da busca por um self autêntico. Na perspectiva adotada pelos autores, o sujeito é sempre local de contestação de horizontes de significado adquiridos por meio das experiências vividas. No caso específico de pessoas cristãs e LGBT, conflitos internos podem surgir em maior ou menor intensidade, a depender do contexto sociorreligioso - se mais conservador ou mais flexível e progressista e das negociações estabelecidas por cada sujeito. Um dos elementos apontados pelos autores é o fato de que a aparente dicotomia entre religião e sexualidade tende a colapsar na medida em que os próprios sujeitos reelaboram sua identidade com vistas ao estabelecimento de um self autêntico.

O momento de sair do armário 3 tem papel fundamental na consolidação dessa identidade integrada, e não mais em conflito. Neste processo de saída, são colocados em disputa percepções majoritariamente heteronormativas advindas de vivências religiosas anteriores, não raro hostis à diversidade sexual e de gênero, e novas interpretações adquiridas que apregoam a sexualidade e/ou identidade de gênero como elementos dados por Deus. Assim, sair do armário - para si e para outros/ as/es - passa a ser um imperativo moral, na medida em que o sujeito não pode esconder ou rejeitar sua real identidade, visto Deus o/a/e fez da forma como é. Seguindo as reflexões de Chris Glaser (1998), o ato de sair do armário, no contexto de igrejas formadas por pessoas LGBT, torna-se um sacramento, na medida em que se trata de um momento de graça e completude que faz com que os sujeitos, de fato, revelem-se a si mesmos para Deus e sejam dotados de um sentimento de que revela seu amor incondicional. Neste sentido, vale rememorar, a título de exemplificação deste processo, que o primeiro sermão de Troy Perry no culto inaugural das MCCs em Los Angeles, no ano de 1968, tinha como tema a passagem bíblica que enfatiza: Be True to You ${ }^{4}$.

Outro fator fundamental neste processo é a reconstrução da identidade individual no sentido de assumir um self autenticamente cristão. O contato com o espaço das ICMs permite que novas negociações sejam

Expressão corrente nos meios de sociabilidade LGBT para se referir a se assumir.

4 Sê fiel a ti mesmo. 
estabelecidas pelos sujeitos. Tais movimentos envolvem tensões nas quais os sujeitos operam distinções entre os ensinamentos da igreja, enquanto instituição, e os ensinamentos de Jesus que, de acordo com pessoas entrevistadas por Fielder e Ezzy, pregou um amor inclusivo. Este processo, que envolve aprendizado, reelaborações, novas interpretações e, fundamentalmente, novas relações com outros sujeitos também cristãos e LGBT, possibilitam a formulação de novos horizontes de significado que impactam a própria forma de se perceber dentro do cristianismo. Ainda que a agência individual seja importante, são as experiências de fé compartilhadas em comunidade que permite aos sujeitos religiosos LGBT sucesso na busca por sua identidade autêntica.

Shaken Worlds é o quinto capítulo da obra, cujo objetivo é compreender como os sujeitos que frequentam as MCCs incluídas no estudo passaram a negociar formas de ser cristãos a partir do momento em que tomaram consciência de que sua orientação sexual e/ou identidade de gênero não correspondia aos padrões heteronormativos característicos dos ensinamentos cristãos que receberam. Para dar conta das análises propostas, Fielder e Ezzy adaptam um esquema metodológico, desenvolvido por Levy e Reeves (2011), para mapear respostas possíveis de indivíduos que tiveram conflitos, ou não, entre sua educação religiosa e a identidade sexual e/ou de gênero.

Para os indivíduos que não passaram por conflitos morais significativos, foram identificadas três respostas iniciais que representam os/as/ es participantes do estudo: 1) confrontação à doutrina; 2) discordância com a doutrina; 3) sigilo/segredo. Esses sujeitos, muito embora esteja cientes dos conflitos sociais existentes entre percepções religiosas cristãs e identidades LGBT, encontram possibilidades de afirmar seu verdadeiro self independentemente da doutrina da igreja. Alguns participantes relataram ter recorrido a estudos teológicos como forma de contra-argumentar interpretações discriminatórias e compreender se a Bíblia, de fato, faz referência à homossexualidade como um pecado. Além disso, o suporte familiar e o fato de, em sua maioria, esses sujeitos relatarem ter crescido em congregações religiosas liberais, também são fatores determinantes para a construção das trajetórias individuais daqueles/as que não experimentam conflitos. Para a maior 
parte destes, a Bíblia é entendida como um livro passível de diferentes interpretações e os principais elementos da fé cristã são o exemplo de Jesus e o amor de Deus.

Com relação aos sujeitos que experimentaram conflitos internos, os autores identificam quatro respostas iniciais: 1) negação da identidade sexual com ou sem aumento do envolvimento religioso; 2) sigilo/ segredo; 3) diminuição do envolvimento religioso com ou sem realocação (mudança de comunidade religiosa); 4) depressão e automutilação. Essas respostas são comumente relacionadas a educação religiosa conservadora e menos flexível que, consequentemente, faz com que os indivíduos neguem sua homossexualidade ou transgeneridade para se manterem dentro da norma. Entrevistados/as/es de Fielder e Ezzy relatam um maior envolvimento religioso depois da percepção de que seus desejos sexuais se chocavam com os horizontes de significado religiosos. Muitos verbalizam constantes orações para que Deus os libertasse daqueles desejos e, inclusive, relatam ter se envolvido em relações heterossexuais, nas quais alguns/as casaram e tiveram filhos/ as/es. Com relação à manutenção de sua identidade em segredo, alguns indivíduos relatam que o fizeram por medo de colocar em risco sua relação com pessoas queridas de seus círculos sociais. Para outros/as/es, o afastamento com relação à igreja é a primeira resposta, seja por vontade própria ou por saberem o posicionamento da igreja com relação às identidades LGBT. O afastamento com relação à igreja, no entanto, não necessariamente significa um descolamento entre o sujeito e Deus - na maior parte dos relatos, essa relação se mantém pelo exercício de uma fé individualizada. Por fim, há sujeitos que expressaram ter lidado com conflitos intensos, que pensamentos suicidas pareciam a única solução diante da possibilidade de ser odiado por Deus e condenado ao inferno.

Tanto para os sujeitos que experimentaram conflitos quanto para aqueles que não passaram por processos similares, a questão do empoderamento individual é fundamental para que haja integração plena entre a sexualidade/identidade de gênero e a religiosidade cristã. É justamente neste aspecto que o ingresso e vivência nas ICMs é premente, pois permite que esses sujeitos encontrem possibilidades de reconstrução de seus horizontes de significado. Este é o ponto 
central que norteia o sexto capítulo, Rebuilding Worlds, no qual os autores enfatizam formas e estratégias de pessoas LGBT cristãs no sentido de reconciliar sua sexualidade e/ou identidade de gênero à sua religiosidade. Neste processo, identificam como chave o que denominam momento catalizador. Incorporando novamente o mesmo esquema analítico de Levy a Reeves (2011), este momento ocorreria a partir de três elementos: 1) reconhecimento da atração por pessoa do mesmo sexo; 2) reenquadramento de aprendizados antigos ou novos aprendizados; 3) experiência emocional e relacional. De forma geral, esses momento catalizador informa aos sujeitos LGBT cristãos que as doutrinas e ensinamentos religiosos são passíveis de questionamento e reinterpretação por meio de novas vivências e formas de sociabilidade em um espaço seguro - neste caso, as ICMs. A partir desses três processos, que ocorrem concomitantemente, é possível aos sujeitos lidar com os conflitos que surgem entre os horizontes de significado e habitus religiosos pregressos e novas formas de experimentar o cristianismo. Nesta etapa, Fielder e Ezzy destacam fatores importantes: 1) busca por informação; 2) discussões e reflexões; 3) relações importantes em um espaço seguro; 4) práticas religiosas em um espaço seguro. Ao encontrar esses elementos prementes dentro da nova rede de sociabilidade religiosa oferecida pelas ICMs, os sujeitos se encaminham então para a resolução do conflito, que permite compatibilizar uma autêntica identidade sexual e/ou de gênero a uma autêntica identidade religiosa.

Vale destacar, ainda, alguns elementos nucleicos à experiência de LGBTs cristãos, apreendidos a partir das entrevistas realizadas por Fielder e Ezzy. O investimento das lideranças pastorais das ICMs em um discurso que apregoa as identidades LGBT como dadas por Deus é componente fundamental no processo de reformulação dos horizontes de significado e da mudança do habitus religioso para esses sujeitos. Apesar deste discurso caracteristicamente essencialista no que concerne à sexualidade e à identidade de gênero, também é necessário enfatizar as formas pelas quais as celebrações religiosas das ICMs exercem um agir performático no campo da prática ritual em atos como, por exemplo, o momento de comunhão, no qual as prerrogativas heteronormativas do cristianismo são suspensas e transgredidas quando pessoas LGBT 
se sentam à mesa e participam do rito. Ao mesmo tempo em que tais atos performáticos nos momentos rituais promovem fissuras que, de certa forma, queerizam o cristianismo, o fazem concomitantemente ao empoderamento dos sujeitos que dele participam, alimentando sentimentos de pertencimento por meio da promoção de um espaço seguro para adoração, do diálogo, das relações e de novas emoções que são capazes de promover, de acordo com os próprios sujeitos da pesquisa, cura e completude. Neste sentido, considera-se que pessoas LGBT cristãs constroem seu próprio espaço dentro do cristianismo - e, portanto, queerizam o cristianismo -, investindo em múltiplas estratégias de aceitação de si como seres autênticos no que concerne à sua identidade sexual e/ou de gênero, assim como no que se refere à identidade religiosa.

O último capítulo da obra leva o título de Untroubled Christianity. Seu objetivo, sugerido no título, é o de demonstrar como, apesar de certa queerização do cristianismo por meio das ações e práticas das ICMs e de sujeitos LGBT cristãos, alguns padrões normativos se repetem dentro desta denominação e nos próprios horizontes de significado de sua membresia. Um dos aspectos, já bastante destacado, refere-se à questão dos essencialismos acionados com o intuito de estabelecer a legitimidade de ser LGBT e cristão como forma de exercer uma identidade autêntica dada por Deus. Os autores também enfatizam que a questão da linguagem inclusiva, embora defendida e estimulada pela FUICM, é por vezes questionada por membros, sobretudo quando se refere a Deus - a utilização de substantivos femininos é relatado com desconforto por alguns/as/es participantes da pesquisa, que declaram, por exemplo, achar desnecessário mudar o gênero de Deus.

Alguns elementos característicos de estruturas patriarcais, predominantes no cristianismo institucional, ainda reverberam nas ICMs, como o fato de alguns participantes do sexo masculino apontarem excessiva emotividade das mulheres. Também foi identificado pelos autores uma implícita valorização da monogamia em detrimento de outras formas de relações afetivo-sexuais. Todos esses aspectos reverberam em dinâmicas de normalização e legitimidade, inclusão e exclusão, estabelecimento daqueles de dentro e de fora, do ser ou não ser parte da congregação 
e, em certa medida, reproduzem os mesmos mecanismos normativos de vertentes cristãs tradicionais e conservadoras. Neste sentido, Fielder e Ezzy, embora considerem as contribuições das ICMs em queerizar o cristianismo, ressaltam que seus limites esbarram em uma espécie de homonormatividade que produz e reforça um novo habitus normativo específico.

As discussões finais da obra retomam os capítulos e principais temas trabalhados ao longo desta. A noção de que pessoas LGBT cristãs são motivadas por uma ética de autenticidade que possui uma legitimação religiosa é premente, pois faz parte de um movimento individual de ser verdadeiro para consigo mesmo. Por conta disso, o momento de coming out, ou seja, de se assumir, é tão central na experiência desses sujeitos. O papel das MCCs na vida de seus membros envolve, fundamentalmente, possibilidades de mudança do habitus religioso como forma de empoderamento em comunidade, potencializado pela experiência religiosa.

Lesbian, Gay, Bisexual and Transgender Christians: Queer Christians, Authentic Selves é uma obra fundamental para compreender dinâmicas específicas que marcam a modernidade religiosa e complexificam os debates que levam em conta a religião, a diversidade sexual e a diversidade de gênero. Auxilia na compreensão do fenômeno religioso e seus impactos na formação da subjetividade dos sujeitos religiosos. Para pessoas LGBT cristãs, como demonstrado por Fielder e Ezzy, a pertença a uma congregação religiosa envolve aspectos concernentes à experiência, às relações e às emoções, penetrando dimensões profundas da constituição individual e coletiva do self. Desta forma, consideramos que a obra traz importantes contribuições que ampliam o campo dos estudos de religião, sobretudo da psicologia da religião e das ciências sociais da religião.

\section{REFERÊNCIAS}

BAUER, Paul F. The Homosexual Subculture at Worship: A Participant Observation Study. Pastoral Psychology, v. 25, n. 2, 1976, 115-127.

BOURDIEU, Pierre. Outline of a Theory of Practice. Cambridge: Cambridge University Press, 1977. 
ENROTH, Ronald M.; JAMISON, Gerald E. The Gay Church. Grand Rapids: Eerdmans, 1974. GLASER, Chris. Coming Out as Sacrament. Louisville: Westminster John Knox Press, 1998. LEVY, Denise; REEVES, Patricia. Resolving Identity Conflict: Gay, Lesbian, and Queer Individuals with a Christian Upbringing. Journal of Gay \& Lesbian Social Services, v. 23, n. 1, 2011, p. 53-68.

LUKENBILL, W. B. Observations on the Corporate Culture of a Gay and Lesbian Congregation. Journal for the Scientific Study of Religion, v. 37, n. 3, 1998, 440-452.

TAYLOR, Charles. The Ethics of Authenticity. Cambridge \& London: Harvard University Press, 1991.

WILCOX, Melissa. Of Markets and Missions: The Early History of the Universal Fellowship of Metropolitan Community Churches. Religion and American Culture: A Journal of Interpretation, v. 11, n. 1, 2001, pp. 83-108.

WILCOX, Melissa. Coming out in Christianity: Religion, Identity \& Community. Bloomington \& Indianapolis: Indiana University Press, 2003.

Submetida em: 25-1-2021

Aceita em: 12-4-2021 